\title{
BMJ Open Students' satisfaction and perceived impact on knowledge, attitudes and skills after a 2-day course in scientific writing: a prospective longitudinal study in Spain
}

\author{
Esteve Fernández, ${ }^{1,2}$ Ana M García, ${ }^{3}$ Elisabet Serés, ${ }^{4}$ Fèlix Bosch ${ }^{4,5}$
}

To cite: Fernández E, García AM, Serés E, et al. Students' satisfaction and perceived impact on knowledge, attitudes and skills after a 2-day course in scientific writing: a prospective longitudinal study in Spain. BMJ Open 2018;8:e018657. doi:10.1136/ bmjopen-2017-018657

- Prepublication history for this paper is available online. To view these files, please visit the journal online (http://dx.doi. org/10.1136/bmjopen-2017018657).

Preliminary results of this study 'Fernández E, García AM, Serés E, Bosch F. Ten years' experience teaching health professionals to write and to publish articles. Available at were presented in poster format at the Seventh International Congress on Peer Review and Biomedical Publications, 8-10 September 2013, Chicago, Illinois, USA.

Received 13 July 2017 Revised 23 November 2017 Accepted 30 November 2017

Check for updates

For numbered affiliations see end of article.

Correspondence to

Dr. Esteve Fernández;

efernandez@iconcologia.net

\section{ABSTRACT}

Objectives This study aimed to determine students' satisfaction with a 2-day course on scientific writing in health sciences and to assess their perceptions of the long-term impact on their knowledge, attitudes and skills. Setting 27 iterations of a 2-day course on writing and publishing scientific articles in health sciences.

Participants 741 students attending the 27 courses. Design Prospective longitudinal study.

Primary and secondary outcome measures Immediately after each course, students completed a first questionnaire, rating their satisfaction with different aspects of the classroom sessions on a Likert scale (0-5). Approximately 2 years after the course, students completed a followup questionnaire, using a Likert scale (0-4) to rate their knowledge, skills and attitudes in relation to scientific writing before and after attending the course.

Results 741 students (70\% women) participated in the 27 iterations of the course; 568 (76.8\%) completed the first questionnaire and $182(24.6 \%)$ completed the follow-up questionnaire. The first questionnaire reflected high overall satisfaction (mean score, 4.6). In the second questionnaire, students reported that the course had improved their knowledge (mean improvement:

1.6; $95 \% \mathrm{Cl} 1.6$ to 1.7), attitudes (mean improvement: $1.3 ; 95 \% \mathrm{Cl} 1.2$ to 1.4 ) and skills (mean improvement: $1.4 ; 95 \% \mathrm{Cl} 1.3$ to 1.4 ) related to writing and publishing scientific papers. Most respondents $(n=145,79.7 \%)$ had participated in drafting a scientific paper after the course; in this subgroup, all the specific writing skills assessed in the second questionnaire significantly improved.

Conclusions Students were satisfied with the format and the contents of the course, and those who responded to the follow-up survey considered that the course had improved their knowledge, attitudes and skills in relation to scientific writing and publishing. Courses are particularly important in countries without strong traditions in scientific publication.

\section{INTRODUCTION}

Publications are the measurable results of scientific activity. However, most health science researchers, especially in
Strengths and limitations of this study

- The study analysed 10 years' experience including 27 iterations of a 2-day course completed by $>700$ health science researchers.

- This is the first systematic evaluation of students' satisfaction and improvements in knowledge, skills and attitudes acquired of such a course in Spain.

- The study measures the perceived gains rather than objectively assessed gains.

- The response rate to the follow-up questionnaire was low.

- Selection bias could have led to overestimation of positive results in the follow-up survey: the more satisfied students or those with more writing successes to report, may have been more likely to participate.

non-English speaking countries, receive little training in scientific writing. ${ }^{1}$ Writing is challenging for researchers, especially for newcomers, who also need publications to advance their careers. ${ }^{2}$

Most researchers are expected to acquire the skills to write scientific papers without formal training, through 'learning by doing'. ${ }^{3}$ Inadequate training in scientific writing can make postgraduate students and established researchers reluctant to write. ${ }^{4}$ In recent decades, the number of courses and workshops on scientific writing have increased, but the effectiveness of these endeavours remains to be determined. ${ }^{5}$

Given the lack of undergraduate courses on scientific writing in Spain, in 2003, we designed and launched a 2-day course on writing and publishing scientific articles for researchers in the health sciences in the early stages of their careers. ${ }^{6}$ This study aimed to determine students' satisfaction with this 


\section{Box Programme of the course.}

\section{First day}

- Introduction to the course

- Writing styles

- Scientific style and other styles.

- Characteristics of scientific writing style.

- Types of texts in scientific publications.

- Starting to write: sentences and paragraphs.

- Exercise: scientific writing styles.

- Exercise: writing of paragraphs.

- The original article: introduction

- Definition and general characteristics of the original article.

- Structure of the original article.

- The title: the article's business card.

- Exercise: good and bad titles.

- The abstract of the original article

- The abstract: essential information.

- Types of abstracts (structured and non-structured) and contents.

- Keywords and the Medical Subject Headings.

- Exercise: editing of an abstract.

- The core of the original article (I)

- The Introduction, Methods, Results and Discussion format.

- The introduction: the background and study's aim.

- The methods: what have we done?

- Exercise: writing an Introduction.

- The core of the original article (II)

- The results: what have we found?

- Principles for text and data presentation.

- The balance between text, tables and figures.

- Exercise: building a table.

- The core of the original article (III)

- The discussion: what does our results mean?

- Structure of the discussion section.

- The conclusions.

- Exercise: analysis of a discussion.

- The bibliography and additional sections of the original article

- Use of bibliography and formats.

- Acknowledgements.

- Funding.

- Competing interests.

\section{Second day}

How to publish an article

- Exercise: where do I submit it?

- Choosing the adequate journal.

- The target audience, language and open access.

- The bibliographic impact factor.

- Preparing the article for submission

- The cover letter.

- Final check.

- Online submission.

- Exercise: writing of a cover letter.

- The editorial process

- The peer review process.

- Standard phases of the editorial process.

- Editorial decision criteria.

- Answering peer review.

Ethical aspects of scientific publication

- Authorship: the International Committee of Medical Journal Editors criteria.

\section{Box Programme of the course. Continued}

- Repetitive publication.

- Competing interests.

- Other ethical aspects for authors, editors and publishers.

- Comprehensive exercise with a manuscript

course and their perceptions regarding its long-term impact on their knowledge, attitudes and skills.

\section{METHODS}

The following sections describe the course, the questionnaire administered in the classroom to evaluate students' immediate satisfaction with the course, and the follow-up questionnaire sent to participants to evaluate their perceptions of the impact of the course.

\section{Course characteristics}

We designed an intensive 2-day classroom course for Spanish-speaking undergraduate or postgraduate degrees in health sciences to cover the basic skills involved in scientific writing based on classic books about scientific writing. ${ }^{3} 7$ The main objectives of the course were to provide basic advice about scientific writing, to present the structure and contents of standard scientific articles and to explain the editorial and peer review processes for health science journals. The course imparted this knowledge over 15 hours, combining lectures with individual and group exercises based on real examples. The syllabus for the first day (8hours) covered scientific writing style, scientific publishing formats and the structure and contents of the original article; the syllabus for the second day (7 hours) covered ethical principles in scientific publishing, selecting a target journal, preparing manuscripts for submission and the editorial and peer review processes. The main topics are detailed in box, the full programme of the course is available at http:// www.esteve.org/en/rc-programa (in Spanish) and most of the contents are included in a book used for reference in the course. ${ }^{8}$ The Esteve Foundation (www.esteve.org) offered the course to institutions throughout Spain. The course targets health science researchers in training or in the initial stages of their careers (eg, undergraduate, postgraduate students, postdoctoral fellows, medical residents etc), since most undergraduate and postgraduate curricula in the health sciences in Spain did not include formal training in scientific writing. Two lecturers (AMG and EF) and the promoter (FB) developed all the contents. The lecturers are professors of epidemiology and public health and have recognised experience as authors, reviewers and editors in national and international journals. During the course, both lecturers are present and actively participate in all the sessions. While one explains a topic, the other stimulates the audience with questions or suggestions, making the teaching more dynamic and participative. The number of students in 


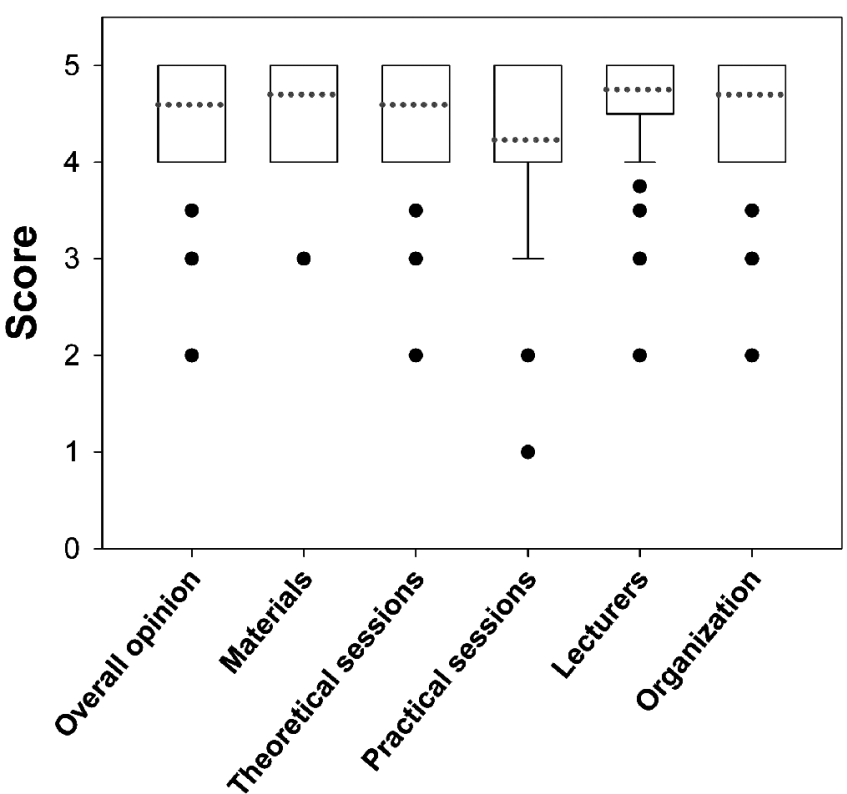

Figure 1 Results of the first questionnaire: students' $(n=569)$ satisfaction with different aspects of classroom sessions in the 27 iterations of the scientific writing course in Spain, 2004-2013. Boxes represent IQRs. Solid lines represent medians, and dotted lines represent means. For all six variables, except "Practical sessions", the median coincides with the upper line of the box. The whiskers represent the 90th and 10th percentiles and the dots represent outliers (each dot represents at least one response).

each edition ranged between 17 and $40 .^{6}$ After a pilot edition during the Minorca Public Health Summer School in 2003, the first edition took place in Valencia in January 2004 and the most recent (44th edition) took place in Bilbao in December 2017. The present study includes data from 741 students participating in the 27 iterations held between 2004 and 2013. The course has been accredited (no 09/013214-MD) by the Catalan Council for Continuing Education in the Health Professions with the approval of the National Health System's Committee on Continuing Education under Spain's Ministry of Health.

\section{First satisfaction questionnaire}

We administered a satisfaction questionnaire at the end of each edition of the course. Each student anonymously rated items on a Likert scale $(0-5)$ presented on printed form. The items queried students about their satisfaction with the course overall, materials, contents of the lectures, contents of the practical exercises, lecturers and organisational aspects. The questionnaire is available at http://www.esteve.org/en/rc-encuesta. We used the same questionnaire without changes in the 27 iterations of the course.

\section{Follow-up questionnaire}

We designed a follow-up questionnaire (available at http://www.esteve.org/en/rc-encuesta-diferido) to collect sociodemographic data and to assess students' perception of the effect of attending the course on their
Table 1 Characteristics of the students who answered the follow-up questionnaire about the course on scientific writing (27 iterations in Spain, 2004-2013)

\begin{tabular}{|c|c|c|c|}
\hline & Total & $\begin{array}{l}\text { Students } \\
\text { who went } \\
\text { on to } \\
\text { collaborate } \\
\text { in preparing } \\
\text { a paper for } \\
\text { publication }\end{array}$ & $P$ value \\
\hline Trainees, $\mathrm{n}$ & 182 & 145 & \\
\hline $\begin{array}{l}\text { Age, mean (SD) } \\
\text { (years) }\end{array}$ & $39.1(9.4)$ & $38.8(9.6)$ & $0.849^{\star}$ \\
\hline \multicolumn{4}{|l|}{ Gender, n (\%) } \\
\hline Women & $131(72.0)$ & $103(71.0)$ & $0.902 \dagger$ \\
\hline Men & $51(28.0)$ & $42(29.0)$ & \\
\hline \multicolumn{4}{|c|}{ Field of degree, n (\%) } \\
\hline Medicine & 66 (36.3) & $56(38.4)$ & $0.981 \dagger$ \\
\hline Pharmacy & $21(11.5)$ & $17(11.6)$ & \\
\hline Biology & $20(11.0)$ & $15(10.3)$ & \\
\hline Others & $75(41.2)$ & $58(39.7)$ & \\
\hline \multicolumn{4}{|c|}{$\begin{array}{l}\text { Main type of research, } \\
n(\%)\end{array}$} \\
\hline Clinical research & $41(22.5)$ & 37 (25.3) & $0.036 \dagger$ \\
\hline Basic research & 95 (52.2) & $89(61.0)$ & \\
\hline Others & $46(25.3)$ & $20(13.7)$ & \\
\hline
\end{tabular}

*Student's t-test.

$+\chi^{2}$ test.

knowledge (5 items), attitudes (3 items), opinions (3 items) and skills (16 items: 3 general skills and 13 specific skills) with regard to scientific writing. The follow-up questionnaire also reassessed students' overall satisfaction with the course through a new question: 'Would you recommend this course to a colleague?'. Respondents rated all items on a Likert scale $(0-4)$. To analyse the impact of the course on specific skills, we restricted the analysis to students who had collaborated in publishing a scientific article after doing the course. We emailed the follow-up questionnaire to the first 174 students (29.3\% responded) in 2006 and to the subsequent 91 students (27.5\% responded) in 2007. In 2013, we emailed the remaining 475 students, asking them to fill out the questionnaire online (22.3\% responded).

\section{Statistical analyses}

We computed means, medians, ranges, $\mathrm{SD}, 95 \% \mathrm{CI}$ and IQRs for the responses to each item in the questionnaire. To compare the characteristics of the subgroup of students in whom the specific writing skills were analysed with those of the entire group of respondents to the second questionnaire, we used [please, use the Greek symbol] ${ }^{2}$ and Student's t-test. To compare the responses on the items in the follow-up questionnaire asking about students' perceptions of their knowledge, 


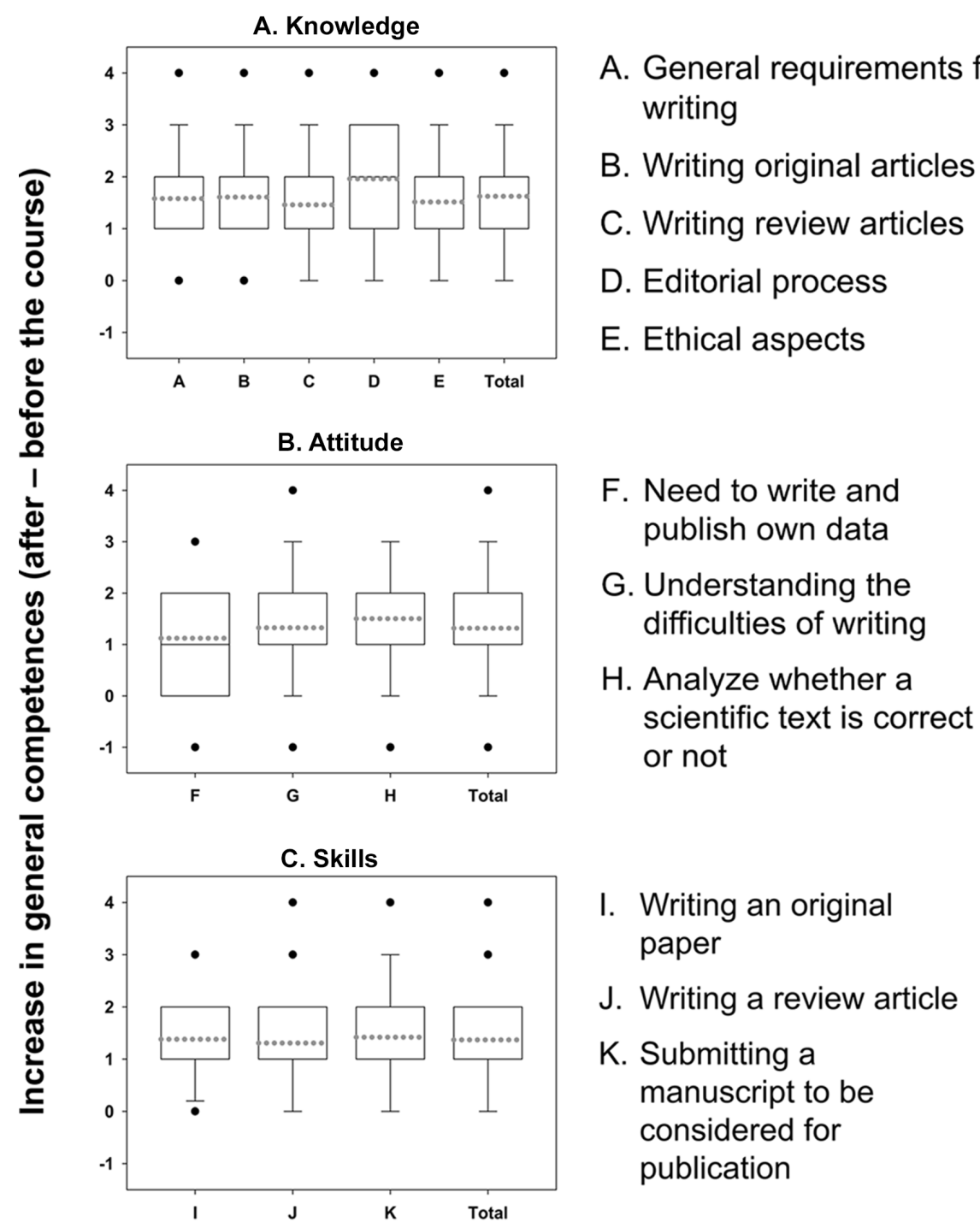

Figure 2 Perceived change in overall competence among students $(n=182)$ who completed the follow-up questionnaire about the scientific writing course (27 iterations in Spain, 2004-2013). The increase in general competence was calculated for each item from individual scores; individual scores were calculated by subtracting the rating on the item asking about competence before and after attending the seminar. Significant gains were observed for all competencies $(P<0.001$; Wilcoxon signed-rank test). Boxes represent IQRs. Solid lines represent medians and dotted lines represent means. For variables $A$ and $B$, the median coincides with the upper line of the box, and for variables $\mathrm{C}, \mathrm{E}, \mathrm{G}, \mathrm{H}, \mathrm{I}, \mathrm{J}$ and $\mathrm{K}$ the median coincides with the bottom line. The whiskers represent the 90th and 10th percentiles and the dots represent extreme values.

skills and attitudes before and after the course, we used the Wilcoxon non-parametric test for paired samples (after-before comparisons). The distribution of the scores (including the predifference and postdifference in scores) is presented using traditional box plots. We used SigmaPlot V.11.0 (Systat Software, Chicago, Illinois, USA) for data processing and statistical analysis.

\section{RESULTS}

A total of 741 students ( $70 \%$ women) attended one of the 27 iterations of the course. The response rate to the first questionnaire was $76.8 \% \quad(\mathrm{n}=569)$. Overall, they rated the experience as very positive (mean 4.6, SD 0.6, of a maximum 5). Students' ratings of satisfaction with the course handouts, theoretical sessions, teachers and overall organisation were above 4.5 (figure 1); only satisfaction with the practical sessions was rated below 4.5 (mean 4.2, SD 0.8).

In the follow-up questionnaire, we obtained a total of 182 responses from 741 students $(24.6 \%$ response rate). Table 1 summarises the general characteristics of these students (age, 39.1 years; 131 (72\%) women) who responded to the follow-up questionnaire and of the subgroup who went on to collaborate in the publication of a scientific paper $(\mathrm{n}=145,79.7 \%$ of the students who responded to the follow-up questionnaire). In the overall group, students had degrees in medicine $(36.3 \%)$, pharmacy $(11.5 \%)$, biology $(11.0 \%)$ or other related fields such as nursing, psychology, biochemistry, biotechnology or statistics $(41.2 \%)$; slightly more than half $(52.2 \%)$ were 


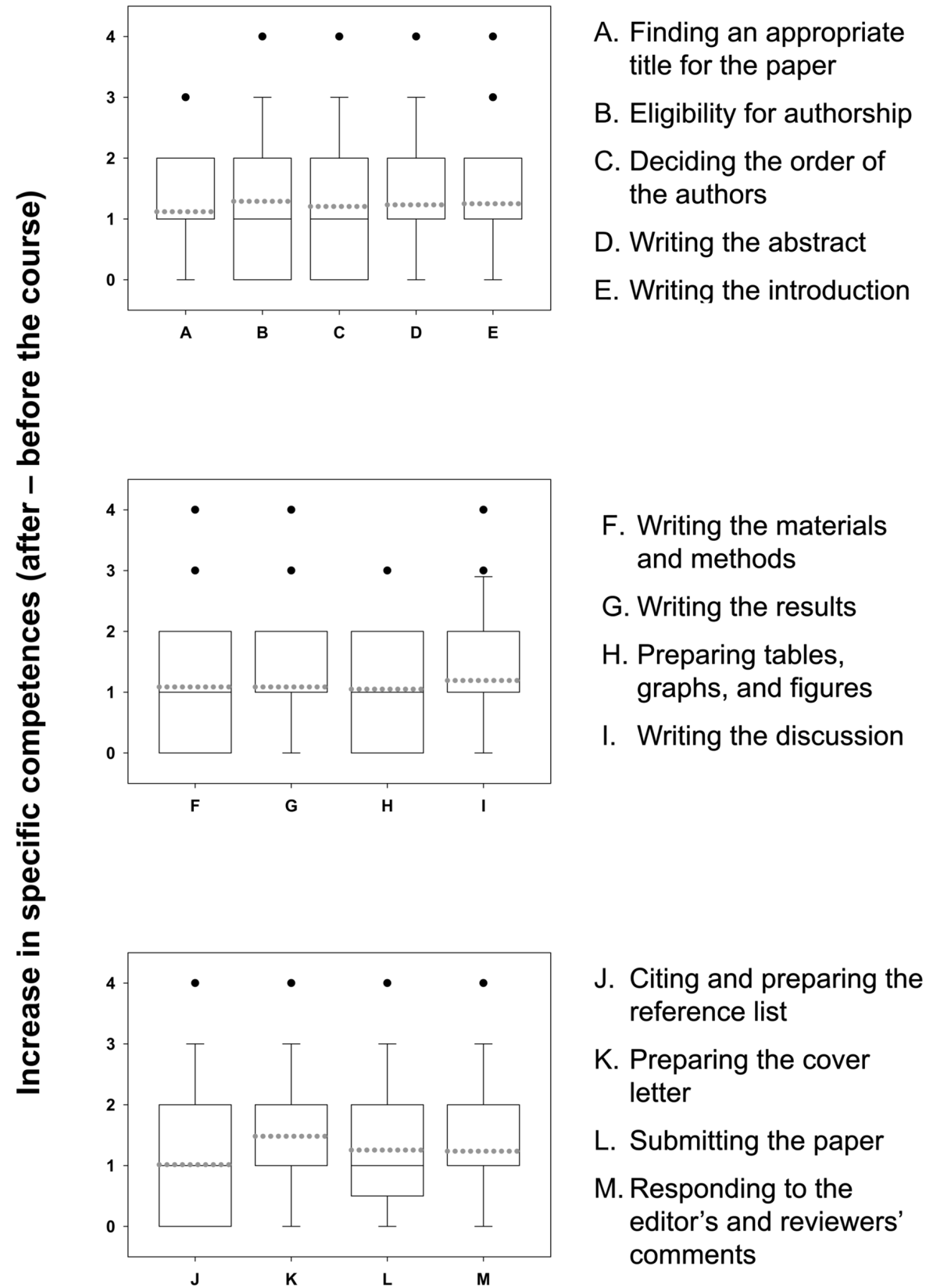

Figure 3 Changes in specific writing skills in students who went on to publish after the scientific writing course ( $\mathrm{n}=145)(27$ iterations in Spain, 2004-2013). The increase in specific writing skills was calculated for each item from individual scores; individual scores were calculated by subtracting the rating on the item asking about competence after attending the seminar from the rating on the item asking about competence before attending the seminar. Significant gains were observed for all general competences $(P<0.001$; Wilcoxon signed-rank test). Boxes represent IQRs. Solid lines represent medians and dotted lines represent means. For variables $A, D, E, G, I$ and K, the median coincides with the bottom line of the box. The whiskers represent the 90 th and 10 th percentiles and the dots represent outliers.

involved in basic research. Students in the subgroup were similar to the entire group of respondents to the follow-up questionnaire in terms of age, gender and undergraduate training, but not in the type of research in which they were mainly involved.

The mean scores for all the items that assessed students' perceptions of their knowledge, skills and attitudes after the course were higher than those for their perceptions of these dimensions before the course (figure 2). Overall increases in scores for knowledge (mean 1.6; 95\% CI
1.6 to 1.7 ), attitudes (mean $1.3 ; 95 \%$ CI 1.2 to 1.4 ) and skills (mean 1.4; $95 \%$ CI 1.3 to 1.4 ) after the course were significant $(\mathrm{P}<0.001)$. Among the items about knowledge (figure 2A), we observed the greatest improvement (2 points) in the understanding of the editorial process. All but five assessments (by four students) yielded higher postcourse scores regarding attitudes toward publishing (figure 2B). Students also indicated the need for training in scientific writing at both the undergraduate (mean score $3.1 ; 95 \%$ CI 2.9 to 3.3 , of a maximum 4) and 
postgraduate level (mean score 3.9 ; $95 \%$ CI 3.8 to 4.0 ). The mean score on the question asking about students' overall degree of satisfaction with the course was 3.8 (SD $0.4)$.

Figure 3 shows the change in perceptions of specific writing skills before and after the course in the subgroup of students who went on to collaborate in the publication of scientific paper. Statistically significant improvements were observed for all the skills $(\mathrm{P}<0.001$; Wilcoxon signedrank test). Average improvements ranged between 1.0 (95\% CI 0.8 to 1.2 ) points for citing and writing references and 1.5 (95\% CI 1.3 to 1.7) for preparing cover letters, with improvements in the remaining skills lying between these values: determining eligibility for authorship (1.3; $95 \%$ CI 1.1 to 1.5$)$, writing introductions $(1.3 ; 95 \%$ CI 1.1 to $1.5)$, writing abstracts (1.2; 95\% CI 1.0 to 1.4$)$, writing discussions (1.2; $95 \%$ CI 1.0 to 1.4$)$ and responding to editors' and reviewers' comments (1.2; 95\% CI 1.0 to 1.4$)$.

\section{DISCUSSION}

This study analysed 10 years of experience that included 27 iterations of a 2-day course on how to write scientific articles. The course was completed by $>700$ health science researchers. The two surveys showed high satisfaction with the 2 day format and the contents of the course. Moreover, the second survey showed that students considered that the course had improved their overall knowledge, attitudes and skills as well as some specific writing skills. Importantly, students expressed the need for this type of training at both the undergraduate and postgraduate levels.

Our results are similar to those of other published experiences, most of which were included in two systematic reviews ${ }^{5}$ that evaluated different outcomes. Like other authors, ${ }^{10}$ we analysed students' satisfaction with the course. Most published accounts report experiences in English-speaking countries (USA, Australia and New Zealand). ${ }^{5}$ Galipeau et al systematic review ${ }^{5}$ included 12 studies focused on writing for publication; most of these had shortcomings like small samples, low validity or biases, so the authors concluded that there are important gaps in our knowledge of how to improve scientific writing.

Jawaid et $a l^{11}$ reported an experience from Pakistan (language of course not stated), with 120 attendees who participated in a 3-month course based on four interactive workshops. Through a preworkshop and postworkshop questionnaire comprising 14 questions, the authors concluded their course improved attendees' knowledge and skills related to writing. One study from the USA $^{12}$ not included in Galipeau et al systematic review ${ }^{5}$ assessed improvements in writing after a 60-90 min case report writing workshop. In a 3-year period, 214 students (mainly clinicians and educators) attended the workshops, and pre-evaluation and postevaluation found a significant improvement in self-rated writing competence and in the perceived probability of submitting a case report. In another study from the USA, Guydish et $a l^{13}$ assessed the impact of a scientific writing seminar aiming to encourage manuscript writing and dissemination of addiction research. Over a 14-year period, a total of 113 postdoctoral students in 14 cohorts completed the 6 month seminar. After the course, between $75 \%$ and $100 \%$ of the students from each cohort submitted papers and between $60 \%$ and $100 \%$ of these were published. The authors concluded that writing seminars may be useful among early-stage investigators.

Regardless of whether scientific writing courses yield positive or negative results, evaluations of their effectiveness have seldom been published. ${ }^{59}$ We consider these activities to be educational interventions, and as such they should have valid study designs under the principles of implementation research, ${ }^{14}$ which seeks to understand and work within real world conditions, rather than try to control for these conditions or to remove their influence as causal effects, as is the case in experimental trials.

Some limitations of our study must be considered. First of all, the satisfaction questionnaire used has not had a formal validation, and the study measures perceived gains rather than objectively assessed gains. Second, while the response rate in the initial satisfaction baseline survey was robust (nearly $77 \%$ ), it was low for the follow-up survey, and it decreased in the successive waves from $29 \%$ to $27 \%$ and $22 \%$. This might reflect difficulties in reaching participants who were in training when they did the course, making them more likely to have changed jobs and professional email addresses. A likely explanation of the low response rate is that students who responded were likely to be those who got the most out of the workshop or had best outcomes to report. Selection bias can lead to overestimation of of either positive or negative results in satisfaction surveys. Another limitation is the lack of a control group, which can clarify interpretation of changes in competence in evaluations of interventions. Further studies should ensure follow-up at a fixed time not very long ( 1 or 2 years) after the course and baseline survey; the ideal time would be long enough to detect the changes supposedly due to the intervention but short enough to minimise attrition and recall bias. Furthermore, the positive effects we observed could be partly due to students' postcourse participation in other activities to improve scientific writing. The follow-up questionnaire did not collect information about such activities. However, we collected information on the impact of the course on collaboration in the writing of papers, as in other studies. ${ }^{1315-17}$

Finally, some strengths of our study merit attention. This is the first regularly held course on scientific writing in Spain, currently with 40 iterations in 15 years and $>1000$ participants to date, and the course is still running. To our knowledge, this is also the first report of a systematic evaluation of students' satisfaction and improvements in knowledge, skills and attitudes acquired through a course of these characteristics in Spain. Although simultaneous assessment of prior and posterior knowledge and skills after the course could be considered a weakness in terms 
of causal inference, it may actually be a strength since the students are more aware and provide more coherent information about the items evaluated and the changes suffered.

In conclusion, the format and contents of the course satisfied the students' needs, and participants who responded to the follow-up survey reported improvement in their skills related to scientific writing and publishing. Participants strongly agreed that health professionals need training in scientific writing during the course of their undergraduate and/or postgraduate studies. Academic institutions, at least in countries with a less robust tradition of publishing, should provide training on scientific writing to improve the reporting of research results.

\section{Author affiliations \\ ${ }^{1}$ Tobacco Control Unit, Institut Català d'Oncologia (ICO-IDIBELL), Barcelona, Spain \\ ${ }^{2}$ Department of Clinical Sciences, School of Medicine, Campus de Bellvitge, Universitat de Barcelona, L'Hospitalet del Llobregat, Barcelona, Spain \\ ${ }^{3}$ Department of Preventive Medicine and Public Health, Universitat de València, Valencia, Spain \\ ${ }^{4}$ Esteve Foundation, Barcelona, Spain \\ ${ }^{5}$ Department of Experimental and Health Sciences, School of Health and Life Sciences, Universitat Pompeu Fabra, Barcelona, Spain}

Acknowledgements The authors wish to thank all the students who participated in the surveys and Pol Morales, Elisabet Caballeria and Laura García from the Esteve Foundation for their contributions to the running of the course and to the evaluation processes. We also thank John Giba for reviewing and revising the English version of the manuscript

Contributors EF, AMG and FB conceived and designed the study. All the authors designed the questionnaires. EF and AMG designed the analysis strategy; ES and $\mathrm{FB}$ analysed the data and all the authors contributed to its interpretation. EF and FB wrote the first draft of the manuscript; all authors contributed substantially to subsequent versions of the manuscript and all authors approved the final version.

Funding The training course described in this study was funded by the Esteve Foundation, a private non-profit foundation under Spanish Law. Some iterations of the course have received partial funding from third parties, such as public universities, public hospitals, public research centers and scientific societies. EF was partly funded by the Department of Universities and Research, Government of Catalonia (2014SGR999).

Competing interests EF and AMG received fees as lecturers for conducting these courses, but did not receive any fee for the design, analysis or writing of this paper. $\mathrm{ES}$ and $\mathrm{FB}$ are employees of the Esteve Foundation, a private non-profit foundation under Spanish Law. ES and FB have participated in the courses and the preparation of this paper as part of their paid work.

Patient consent Not required.

Ethics approval Participants provided informed consent to participate in the study (oral consent for the first satisfaction questionnaire and written consent for the follow-up questionnaire). As the surveys were conducted as part of the routine evaluation of the course, as approved by the Council for Continuing Education, no further ethics approval was required.

Provenance and peer review Not commissioned; externally peer reviewed.

Data sharing statement A full data set of results is available from the corresponding author.

Open Access This is an Open Access article distributed in accordance with the Creative Commons Attribution Non Commercial (CC BY-NC 4.0) license, which permits others to distribute, remix, adapt, build upon this work non-commercially, and license their derivative works on different terms, provided the original work is properly cited and the use is non-commercial. See: http://creativecommons.org/ licenses/by-nc/4.0/

(c) Article author(s) (or their employer(s) unless otherwise stated in the text of the article) 2018. All rights reserved. No commercial use is permitted unless otherwise expressly granted.

\section{REFERENCES}

1. Marusic A, Marusic M. Small scientific journals from small countries: breaking from a vicious circle of inadequacy. Croat Med $J$ 1999;40:508-14.

2. Albert T. Writing for journals: a paradigm lost? J Epidemiol Community Health 2000;54:642-3.

3. Day RA. How to write and publish a scientific paper. Phoenix: The Oryx Press, 1998.

4. Huston P. Resolving writer's block. Can Fam Physician 1998;44:92-7.

5. Galipeau J, Moher D, Campbell C, et al. A systematic review highlights a knowledge gap regarding the effectiveness of health-related training programs in journalology. J Clin Epidemiol 2015;68:257-65.

6. Morales P, García L, Bosch F. Dos décadas de actividades puente entre la farmacología, la epidemiología y la salud pública en España. Gac Sanit 2015;29:224-7.

7. Huth EJ. How to write and publish papers in the medical sciences. Philadelphia: ISI Press, 1982.

8. Mabrouki K, Bosch F. Fundación Dr Antonio Esteve. Redacción científica en biomedicina: Lo que hay que saber. Barcelona, 2007.

9. McGrail MR, Rickard CM, Jones R. Publish or perish: a systematic review of interventions to increase academic publication rates. High Educ Res Dev 2006;25:19-35.

10. Phadtare A, Bahmani A, Shah A, et al. Scientific writing: a randomized controlled trial comparing standard and on-line instruction. BMC Med Educ 2009;9:27.

11. Jawaid M, Masood Z, Alam SN, et al. An analysis of interactive hands-on workshops on medical writing. J Pak Med Assoc 2011;61:66-70.

12. Sridhar AR, Willett LL, Castiglioni A, et al. Scholarship opportunities for trainees and clinician educators: learning outcomes from a case report writing workshop. J Gen Intern Med 2009;24:398-401.

13. Guydish J, Masson C, Flentje A, et al. Scientific writing seminar for early-stage investigators in substance abuse research. Subst Abus 2016;37:238-41.

14. Peters $\mathrm{DH}, \mathrm{Adam} \mathrm{T}$, Alonge $\mathrm{O}$, et al. Implementation research: what it is and how to do it. BMJ 2013;347:f6753.

15. Files JA, Blair JE, Mayer AP, et al. Facilitated peer mentorship: a pilot program for academic advancement of female medical faculty. $J$ Womens Health 2008;17:1009-15.

16. Rickard CM, McGrail MR, Jones R, et al. Supporting academic publication: evaluation of a writing course combined with writers' support group. Nurse Educ Today 2009;29:516-21.

17. Steinert Y, McLeod PJ, Liben S, et al. Writing for publication in medical education: the benefits of a faculty development workshop and peer writing group. Med Teach 2008;30:e280-5. 